\title{
Analysis of Special Strong Wind and Severe Rainstorm Caused by Typhoon Rammasun in Guangxi, China
}

\author{
Xiakun Zhang1, Jian Chen ${ }^{2 *}$, Zhenquan Lai², Liping Zhai' ${ }^{2}$ Mo Lin ${ }^{3}$ \\ ${ }^{1}$ National Meteorological Center of CMA, Beijing, China \\ ${ }^{2}$ Guangxi Meteorological Observatory, Nanning, China \\ ${ }^{3}$ Guangxi Meteorological Disaster Mitigation Institute, Nanning, China \\ Email: ${ }^{*}$ cjqxt001@163.com
}

How to cite this paper: Zhang, X.K., Chen, J., Lai, Z.Q., Zhai, L.P. and Lin, M. (2017) Analysis of Special Strong Wind and Severe Rainstorm Caused by Typhoon Rammasun in Guangxi, China. Journal of Geoscience and Environment Protection, 5, 235-251. https://doi.org/10.4236/gep.2017.58019

Received: December 30, 2016

Accepted: August 7, 2017

Published: August 10, 2017

Copyright $\odot 2017$ by authors and Scientific Research Publishing Inc. This work is licensed under the Creative Commons Attribution International License (CC BY 4.0).

http://creativecommons.org/licenses/by/4.0/

\begin{abstract}
Based on conventional meteorological observation data, NCEP $1^{\circ} \times 1^{\circ}$ reanalysis data, reanalysis data with resolution $0.75^{\circ} \times 0.75^{\circ}$ from ECMWF and Doppler weather radar, we analyzed the weather conditions and physical characteristics of Super Typhoon Rammasun (1409), which caused special strong wind and severe rainstorm in Guangxi. The results show that: 1) Typhoon Rammasun offshore sudden strengthening in one of the main reasons was that loop pressure ridge superimposed into the westward extension of subtropical high, to making enable rapid strengthening of the subtropical high, so the subtropical high advanced faster than the Rammasun move, Rammasun center of the subtropical high distance reduced and the gradient increased;2) Rammasun northward to south china coast with plenty of vapor following ITCZ, before landing, southwest monsoon and cross-equatorial flow were involved, Rammasun got latent heat of monsoon jet, enabling it to strengthen in offshore; 3) Rammasun from the Qiongzhou Strait into the northern Gulf, therefore the Strait of short passages and both sides belong to the low zone, friction consumption smaller, that was the main reason what was able to maintain the strength of the super typhoon, when Rammasun into the Beibu Gulf; 4) Diagnostic analysis shows that Rammasun before entering the northern Gulf and into the Beibu Gulf later, vorticity weakened, divergence and vapor flux divergence changed were smaller, meanwhile, vertical ascent speed and latent heat transport both increased, which was important reason of severe rainstorm caused by Rammasun.
\end{abstract}

\section{Keywords}

Typhoon Rammasun, Strong Wind, Severe Rainstorm, Cause Analysis, Guangxi 


\section{Introduction}

The typhoon "Rammasun" (super typhoon level) is one of the major disaster weather events that seriously affected South China. Due to its influence, the strong winds and severe torrential rains in Hainan, Guangdong and Guangxi caused significant personnel casualties and property losses, to achieve large-scale meteorological disaster levels. The "Rammasun" before landing in Wenchang of Hainan province, suddenly increase in strength, from 10:00 on July 17. The central intensity of 35,970 continued to strengthen to July $18,14: 00$ center strength 60,915 . Landing in Xuwen of Guangdong province, at 20:00 on July 20, the "Rammasun" enhanced to the central intensity of 60,910. Into the northern Gulf of the sea, the intensity has weakened. At 19:00 on July 19, the center strength of 52,935, down to 16 from 17. Compared with the intensity of the Gulf of Tonkin significantly weakened into difference of strong typhoon in previous years through Hainan Island or Leizhou Peninsula, with the "Rammasun" landing the North Bay, the wind speed is very small, still maintain a super typhoon intensity. So with the third landing Fangchenggang in Guangxi, the center of the wind is still 15 , and accompanied by heavy rain. Winds set off coastal waves, resulting in coastal aquaculture facilities and marine products suffered devastating damage. After verification, the "Rammasun", strong winds with the destructive power, is the strongest typhoon records since the weather records in 1949 in Guangxi. Due to the intensity of the "Rammasun" and the extreme nature of the disaster, it is necessary to analyze the reason why the intensity of the anomaly increases suddenly in the coastal waters and reaches the super-intensity level after entering the northern Gulf, so as to provide reference for future similar process forecast.

In the past studies, it is generally believed that the change of typhoon intensity mainly depends on the three factors of ambient airflow, typhoon structure and ocean condition (Duan Yihong, et al., 2005) [1]. The rapid intensification of tropical cyclones in the coastal waters of South China occurred mainly in the east-west-low-type, north-high-south-type and weak-background conditions (Lin Liangxun, et al., 2006) [2]. In the three circulation regimes, the intensification of the southwest monsoon and the transport to the northern South China Sea, the northward of the cross-equatorial current, the westward transmission of the easterly waves, the invasion of weak cold air and the induction of the short wave channel of the westerly wind are all closely related to the enhancement of tropical cyclones. And the rapid increase of TC induced by southwest monsoon was the most common. Kong Ningqian, et al. (2007) [3] conducted a statistical analysis of tropical cyclones active in the central and northern South China Sea during 1960-2002, and summarized the climatic characteristics of TC intensity abrupt change in the central and northern SCS. It is pointed out that the major weather systems affecting tropical cyclone intensity variation are the subtropical high, the tropical convergence zone, the southwest monsoon trough, the westerly trough and the typhoon. And the subtropical high is the most frequent. $\mathrm{Hu}$ Chunmei, et al. (2005) [4] analyzed large-scale TCs of two types of TCs, which 
were rapidly weakened and rapidly strengthened before landfall in South China. It was concluded that low-level convergence and high-level divergence of TC were strong and it had sufficient water vapor. These research results have important significance of guiding to judge whether typhoon is strengthened in South China coastal waters. The analysis of the "Rammasun" shows that its movement is in the background of low circulation, and the intensification of the subtropical high, the southwest monsoon and the cross-equatorial air entrainment are the important reasons for the sudden intensification of the offshore intensity. And through the low zone of Qiongzhou Strait into the northern Gulf is an important reason to maintain its strength at super-level. In this paper, we use the conventional meteorological data, the NCEP $1.0^{\circ} \times 1.0^{\circ}$ reanalysis data and the European high resolution reanalysis data $\left(0.75^{\circ} \times 0.75^{\circ}\right)$ to analyze the cause of heavy rain and weather and dynamic diagnostic caused by the "Rammasun", which will accumulate the experience for the typhoon forecast.

Strengthening typhoon monitoring and forecasting is an important measure to reduce typhoon disaster. The detection of typhoons mainly uses meteorological satellites. In the satellite cloud, you can clearly see the presence and size of the typhoon. The use of meteorological satellite data to determine the location of the typhoon center, the estimated typhoon intensity, monitoring the direction, speed of typhoon movement, the emergence of storms and other areas, to prevent and mitigate the typhoon disaster plays a key role. When the typhoon arrived in the sea, the radar can also be used to monitor the typhoon. The establishment of the city's early warning system improves the emergency response capability and the establishment of emergency response mechanism. There are also weather forecasters, according to the various information obtained, the analysis of the trend of typhoons and the landing location and time, timely release of typhoon forecasts and typhoons or emergency warning, through television, radio and other media for the public service, fishing vessels in time to shelter, at the same time for all levels of government to provide decision-making basis, the release of typhoon forecast or alarm is an important measure to reduce typhoon disaster.

\section{An Overview of Typhoon}

The "Rammasun" generated in the north-west Pacific on July 12, 2014, and landed in the central coast of the Philippines in evening on July 15, and became the super typhoon in the South China Sea at 5:00 on July 18. At 18:30 on July 18, landing in Wengtian Town, Wenchang City, Hainan Province, the maximum wind speed near the center of the landing is $60 \mathrm{~m} / \mathrm{s}$ (17 levels). At 18:30 on July 18 landing in Long Town coastal, Xuwen County, Guangdong Province with the same intensity once again. At 7:00 on July 19 third landing in Guangpo town coast, Fangchenggang City, Guangxi province, the maximum wind speed near the center of landing is $48 \mathrm{~m} / \mathrm{s}$ (15, strong typhoon level). After landing, it went by Gang Kouqu and Fang Chengqu in Fang Chenggang City of Guangxi province (Weakened to Typhoon level), Shangsi County, Ningming County in 
Chongming City, Longzhou County (weakened to a strong tropical storm level), finally into the northern Vietnam (Figure 1(a)). In this paper, conventional meteorological data from China Meteorological Data Network, combined with mesoscale automatic station monitoring data, then we get Figure 1 through analysing these data. At 20:00 on July 20, entering the territory of Yunnan Province, it weakened into a tropical depression. And at 20:00 on July 20 stopping the number. According to the records of typhoons in Guangxi since 1949, the "Rammasun" is the strongest typhoon ever recorded since landing in Guangxi. The "Rammasun" caused the northern Gulf 14 - 15 sea level, wind gust 17 winds. According to the measured data, the wind power of Weizhou Island reached $59.4 \mathrm{~m} / \mathrm{s}$ (17 class), and the ferry pier of Fangcheng port is $56.5 \mathrm{~m} / \mathrm{s}$ (17 grades). It is the most affected typhoon. There are 9 cities (cities of Beihai, Fangchenggang, Qinzhou, Nanning, Chongzuo, Yulin, Wuzhou, Guigang, Laibin and other 36 cities and counties) with average wind speed of 8 or more, gusts of $10-14$ winds, and the wind in three cities above11 lasted 9 - 11 hours.

The statistics showed that the region has 10 cities appeared heavy rain at 18:00 on July 18 at 20:00 on July 20 . And precipitation of $300-550 \mathrm{~mm}$ in 12 counties (districts) of 23 townships, $200-300 \mathrm{~mm}$ in 18 counties (districts) of 50 townships, $100-200 \mathrm{~mm}$ in 59 counties (districts) of 312 townships. The largest rainfall in Beihai City Hepu County Changle Town, is $552 \mathrm{~mm}$ (Figure 1(b)). Ningming County daily rainfall $(18,20: 00-19,20: 00)$ breaking the historical extreme. By the end of July 23, 17, the "Rammasun", affecting 4.32 million people, a total of 11 cities and 57 counties (cities, districts) in Guangxi, including 10 people died, and causing direct economic losses of 13.84 billion yuan, is a large meteorological disaster.

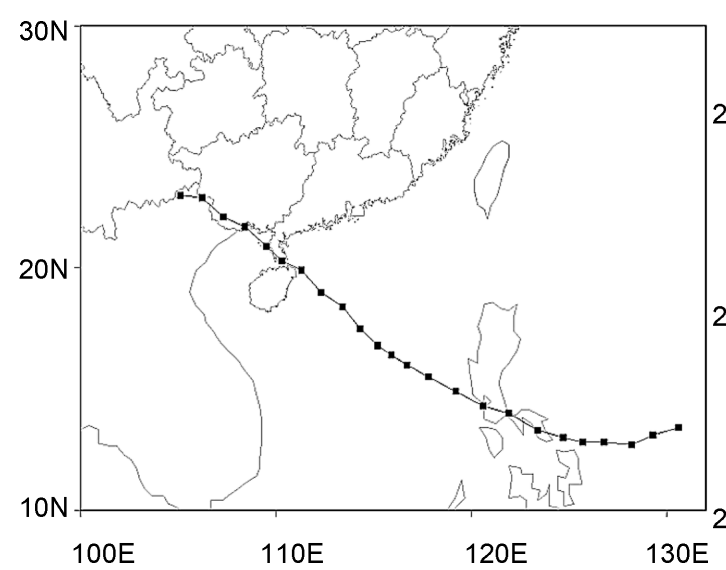

(a)

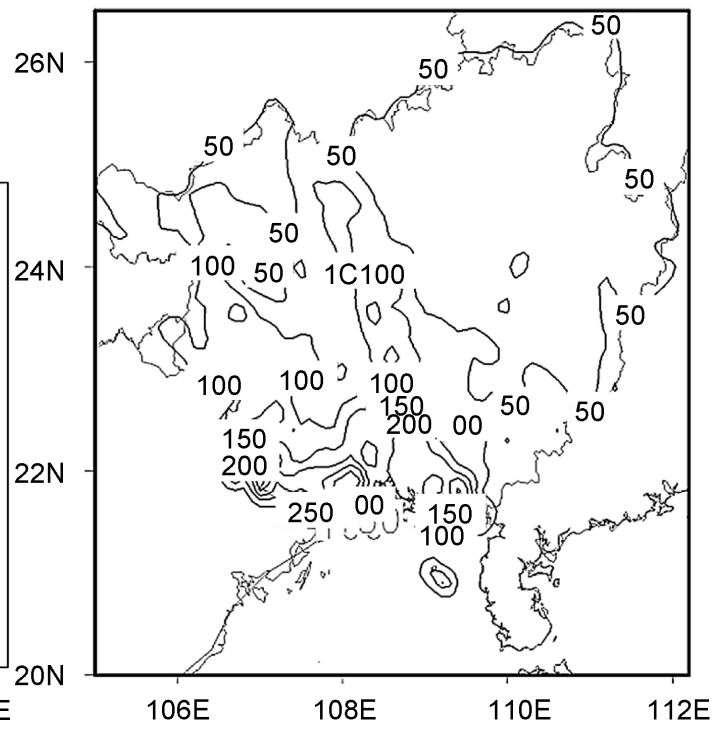

(b)

Figure 1. Track of Typhoon Rammasun (1409) and distribution of rain ((a) Track of Typhoon Rammasun; (b) distribution of rain). 


\section{Weather Situation Analysis}

\subsection{Guided Airflow Analysis}

During the landing period of the "Rammasun" number, on the map of $500 \mathrm{hPa}$ altitude, the subtropical high as a whole is very strong, and 5880dagpm line covers a wide range.

And in the western Pacific there is always a high-value area of the 5920dagpm closed contour (Figure 2). For the convenience of analysis, July 17 as the "Rammasun" movement path of the early and late demarcation point. In the early stage of activity, on July 14, the development of the subtropical high is most powerful, with subtropical high center to 5960dagpm. Before and after the "Rammasun" landing in the Philippines, by the impact of the North China East slot, the subtropical high adjusted little, and 5880dagpm covering part of the South China Sea has been shrinking. At 15:00 on July 15, the west ridge point withdrawing to $114^{\circ} \mathrm{E}$, the subtropical high ridge lining at $22^{\circ} \mathrm{N}, 5880$ dagpm covering southern China to the central Philippines, a strong subtropical high led early the "Rammasun" westbound in the lower latitude. And landed in the south-central Philippines (Figure 2(b)).

After entering the South China Sea, the westward ridge of the subtropical high retreated to $114^{\circ} \mathrm{E}$ on 17 July (Figure 2(a)), and the short-term adjustment to the "Rammasun" provided the northwestward migration Component. At this time although the subtropical high area and intensity has been reduced, but the intensity is still large, showing a square head control of the southeast to the Philippines area. On 18 - 19 July, the northward trough of the North China trough weakened northward, and the Hetao high-pressure ridge moved eastward to the north of the westward extension of the subtropical high. At the same time, the ridge line was gradually increased to the north, so that the "Rammasun" moved steadily to the northwest until it landed in Hainan, Guangdong and Guangxi.

In order to quantitatively analyze the process of adjustment and enhancement of subtropical high, the ridge line, west ridge point, area index and intensity index, which are the characters of the subtropical high features, are analyzed and
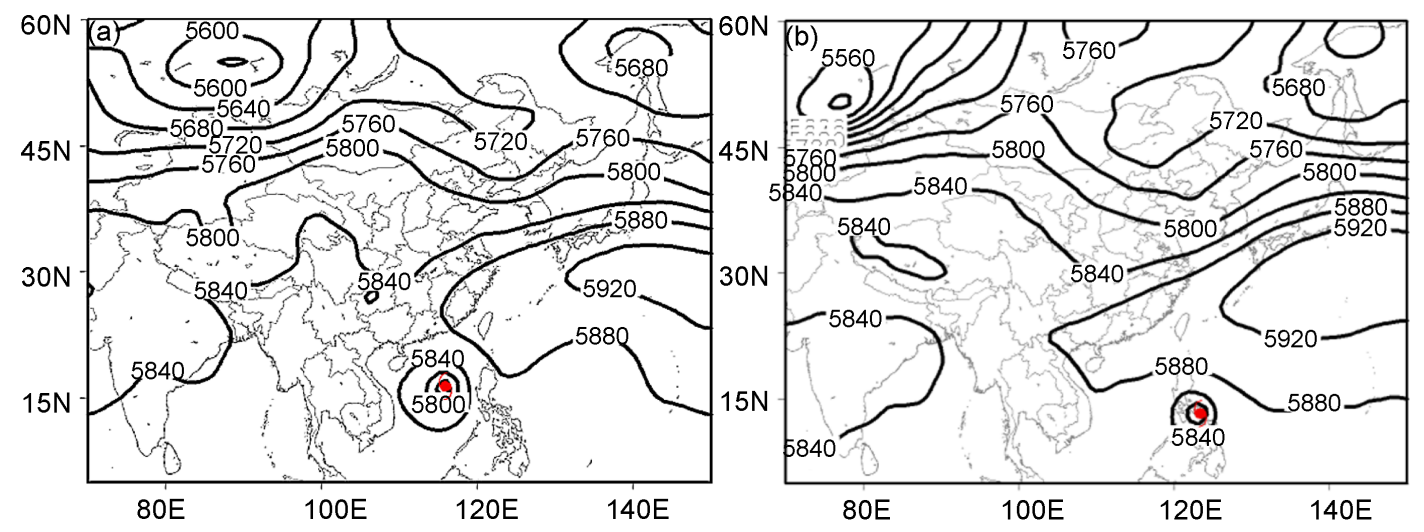

Figure 2. Geopotential height field of $500 \mathrm{hPa}$ ((a) 08:00 BT 17 July 2014; (b) 20:00 BT 15 July 2014). 
calculated day by day (Table 1). Subtropical high ridge refers to the subtropical high pressure contour line anti-cyclone curvature of the largest point of the line or high pressure area east and west westerly line. The longitude of the 588dgam contour in the range of $90^{\circ} \mathrm{E} \sim 180^{\circ} \mathrm{E}$ is defined as the Subtropical high west ridge point. Subtropical high area index is in the range of $110^{\circ} \mathrm{E} \sim 180^{\circ} \mathrm{E}$ north of $10^{\circ} \mathrm{N}$, the average potential height is greater than $588 \mathrm{dgam}$ grid points. The difference between the potential height value and the $587 \mathrm{dgam}$ of the average potential height greater than 588 dgam grid points is accumulated (i.e., 588 is 1 , 589 is 2 ). This cumulative value is the Secondary high intensity index. Where: $500 \mathrm{hPa}$ subtropical high area index: $\left(20^{\circ} \mathrm{N} \sim 55^{\circ} \mathrm{N}, 110^{\circ} \mathrm{E} \sim 140^{\circ} \mathrm{E}\right) \geq$ the sum of the points of 5880dagpm. Strength index: $\left(20^{\circ} \mathrm{N} \sim 55^{\circ} \mathrm{N}, 110^{\circ} \mathrm{E} \sim 140^{\circ} \mathrm{E}\right) \geq$ the sum after the difference between 588 grid point -587 . In table, the subtropical high is strongest on 14 July, and July $15-17$ has weakened, and July $18-19$ has strengthened again, and ridge line lifted northward after July 17 also, finally to $30^{\circ} \mathrm{N}$ on 19 July.

From the "Rammasun" path changes can be analyzed, when the subtropical high adjusted on July 16, 17, the "Rammasun" path began to bend. After the strengthening of the subtropical high on July 18 and 19, the "Rammasun" moved steadily to the northwest and went deep into southern Guangxi, northern Vietnam and southern Yunnan.

\subsection{0 hPa Disturbance Height Analysis}

According to Qian Weihong's physical decomposition method of atmospheric variables, Height field (Figure 3) of the $500 \mathrm{hPa}$ perturbation in the later stage of the "Rammasun" activity was obtained by using the European high resolution reanalysis data $\left(0.75^{\circ} \times 0.75^{\circ}\right)$ from July 17 th to 19 th.

In the figure, the subtropical high enhancement is represented by the disturbance height +20 dagpm line, and the "Rammasun" strength is represented by the central negative perturbation height. From July 17 to 19 , the height of the subtropical high disturbance +20 dagpm line from Taiwan nearby advanced to southern China rapidly, and the coverage increased rapidly also. This is caused by the high disturbance ridge of the continental ridge, which is eastward of the Hetao, to the westward extension of the subtropical high. The velocity of the subtropical high is higher than that of the "Rammasun". The distance between the subtropical high and the typhoon is getting closer and closer, and the pressure gradient is increasing. This is the important reason for the sudden enhancement of the "Rammasun" offshore.

Table 1. The subtropical high activity characteristics index of 13 - 19 July 2014.

\begin{tabular}{cccccccc}
\hline Date & 13th & 14 th & 15 th & 16th & 17th & 18th & 19th \\
\hline Subtropical high ridge $\left({ }^{\circ} \mathrm{N}\right)$ & 24 & 23 & 22 & 24 & 27 & 28 & 30 \\
Subtropical high west ridge point $\left({ }^{\circ} \mathrm{E}\right)$ & 102 & 104 & 103 & 112 & 114 & 110 & 106 \\
Subtropical high area index & 87 & 86 & 80 & 53 & 53 & 83 & 89 \\
Secondary high intensity index & 223 & 256 & 243 & 165 & 146 & 176 & 217 \\
\hline
\end{tabular}




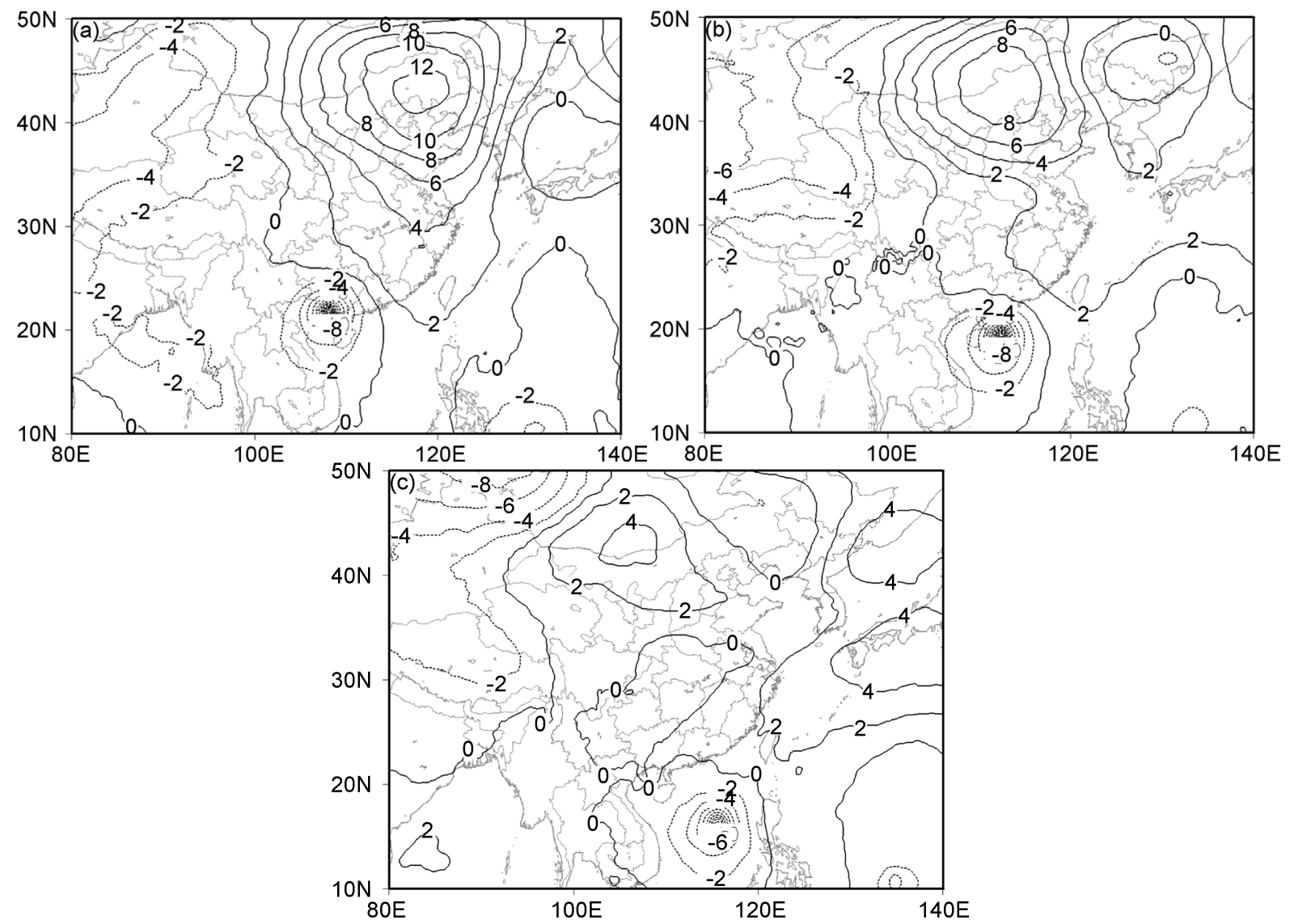

Figure 3. Disturbance height field of $500 \mathrm{hPa}$ ((a) 08:00 BT 19 July 2014; (b) 08:00 BT 18 July 2014; (c) 08:00 BT 17 July 2014).

At 17:00 on July 17th, the height of the "Rammasun" center was -200dagpm, and the height of subtropical high disturbance + 20dagpm line was near Taiwan. And substantially coincides with the edge of the subtropical high at this time. (Figure 3(c)) The center strength of the "Rammasun" is 35,970, and it moves to the northwest with a displacement speed of $22 \mathrm{~km} \cdot \mathrm{h}^{-1}$, which is about $950 \mathrm{Km}$ from the center of the "Rammasun".

At 8:00 on July 18, the center of the "Rammasun", the disturbance height at $320 \mathrm{dagpm}$, deepened the 120dagpm than the 17th. The height of the subtropical high disturbance +20 dagpm line is located in the southeast of China, about 675 $\mathrm{Km}$ from the center of the "Rammasun" (Figure 3(b)). The "Rammasun" center strength is 55,930, to: northwest, speed: $20 \mathrm{~km} \cdot \mathrm{h}^{-1}$. In 24 hours, the wind speed increased by $20 \mathrm{~m} \cdot \mathrm{s}^{-1}$ and air pressure dropped $40 \mathrm{hPa}$, which have reached a sharp increase in the standard (Yan Junyue, 1995, Lin Liangxun, et al., 2006). This is closely related to the rapid advancement of the $275 \mathrm{Km}$ at the front of the subtropical high disturbance height. Then, the "Rammasun" continued to strengthen. At 15:00 on July 18, the central intensity was 60,910 , and the typhoon eye area was clear and dense.

At 8:00 on July 19, the height of the "Rammasun" center was -300dagpm, and the height of the subtropical high + 20dagpm line was located in South China, 
$620 \mathrm{~km}$ away from the center of the "Rammasun" (Figure 3(a)). At this time, the intensity of the "Rammasun" is 48,950 , moving to the northwest and moving at $20 \mathrm{~km} \cdot \mathrm{h}^{-1}$. It is still the strongest typhoon since the meteorological record.

\subsection{Monsoon Low Pressure and 850 HPa Disturbance Velocity Analysis}

During the period of the growth to the landing process of the "Rammasun", the sea southwest warm and humid air constantly inject energy, which is beneficial to strengthen and maintain its intensity. At 20:00 on July 15, 2014, monsoon low pressure was in the northern Indian peninsula, with 5840dagpm closed contour (Figure slightly). At 17:00 on July 17, monsoon low pressure was still located in the northern Indian peninsula, with 5760dagpm closed contour. The enhancement of monsoon low pressure and the increasement of the front of low-pressure of the southwest airflow play an important role in the transport of the low water vapor and unstable energy. After July 17, the "Rammasun" with the northern belt of tropical convergence zone, cross-equatorial airflow simultaneously northward. At 8:00 on the 18th, the "Rammasun" moved to latitude 19 degrees near.

The circulation converges with the enhanced monsoon and trans-equatorial airflow, and the strength of the "Rammasun" is significantly stronger than the previous day and reaches the super-class quickly.

From the analysis of $850 \mathrm{hPa}$ wind field perturbations (Qian Weihong, 2012) [5], southwest monsoon strengthening day by day (Figure 4) from 17 - 19 on July. At 8:00 on July 17th, the vortex center of the "Rammasun" is the body circulation (Figure $4(c)$ ). At 8:00 on July 18th, the vortex center of the "Rammasun" had the southwesterly flow and the cross-equatorial airflow involved (Figure 4(b)). At 8:00 on July 19, the vortex center of the "Rammasun" was integrated with the southwest monsoon (Figure 4(a)). Under the influence of monsoon and cross-equatorial flow, the "Rammasun" is supplemented with sufficient water vapor and unstable energy to strengthen and maintain the strength.

\section{Physical Quantity Field Analysis}

\subsection{Dynamic Condition Analysis}

In order to know more about the changes of the physical quantity field at the important time of the "Rammasun" strengthening at offshore, we draw the data of 8:00 $\left(19^{\circ} \mathrm{N}, 112.3^{\circ} \mathrm{E}\right)$ on July $18,14: 00\left(19.9^{\circ} \mathrm{N}, 111.3^{\circ} \mathrm{E}\right)$ on July $18,8: 00$ $\left(21.7^{\circ} \mathrm{N}, 108.4^{\circ} \mathrm{E}\right)$ on July 19.

The vertical distribution of vorticity field, divergence field, and vertical ascending velocity along the typhoon center near the center of the typhoon is shown in Figure 5.

Figure 5(c) shows that at 08:00 on 18 July, the positive vorticity of the "Rammasun" center has a contour of $80 \times 10^{-6} \mathrm{~s}^{-1}$. And the positive vorticity center extends from $1000 \mathrm{hPa}$ to $100 \mathrm{hPa}$ and forms Vortex column. Figure 5(b) shows 


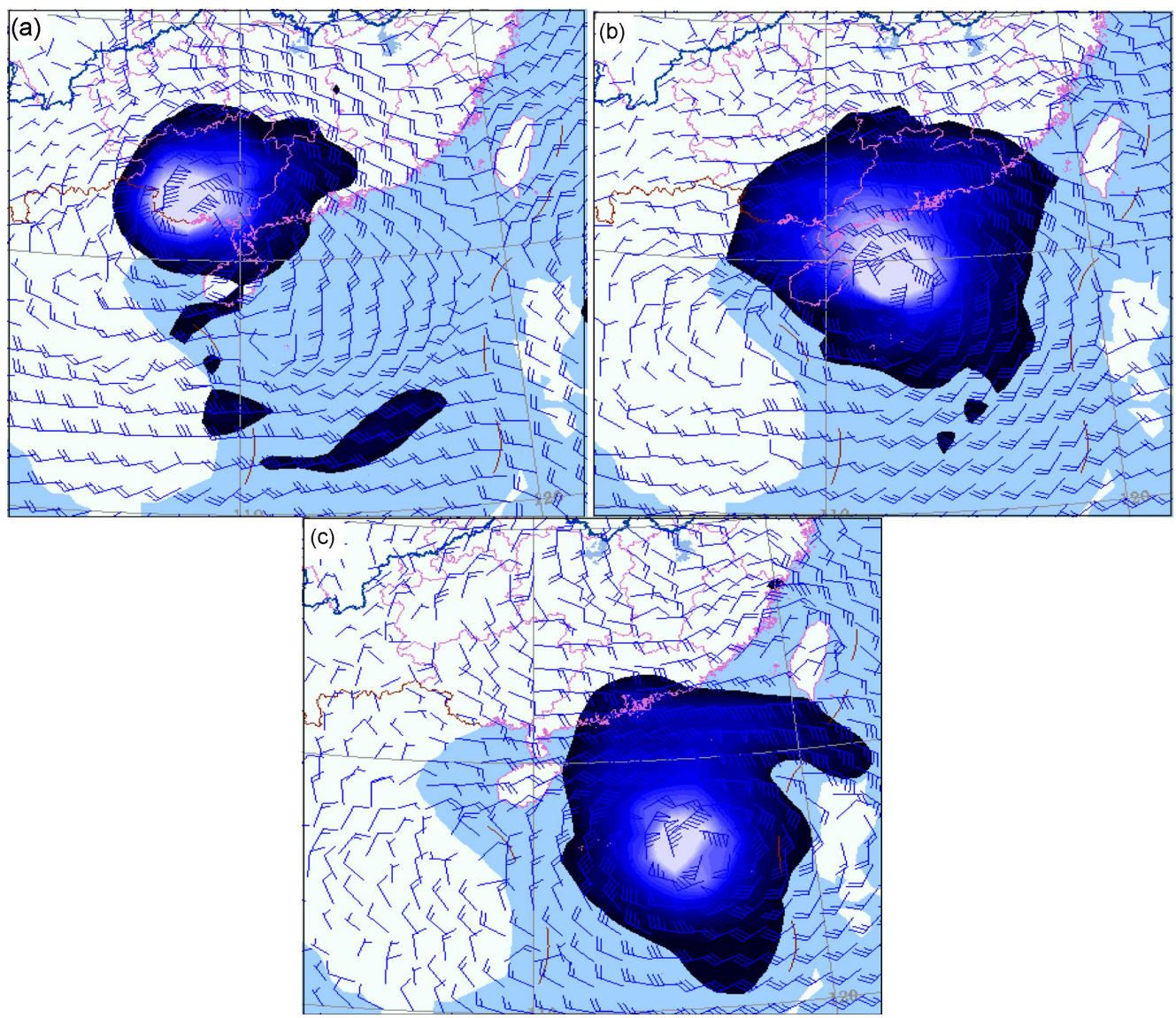

Figure 4. Disturbance wind speed field of $850 \mathrm{hPa}$ ((a) 08:00 BT 19 July 2014; (b) 08:00 BT 18 July 2014; (c) 08:00 BT 17 July 2014).

that, at 14:00 on July 18, Before the "Rammasun" being about to land in Hainan, the central positive vorticity was $70 \times 10^{-6} \mathrm{~s}^{-1}$, with vortex column erect upright and structured clear. Figure 5(a) shows that, at 08:00 on July 19, the positive vorticity was still $60 \times 10^{-6} \mathrm{~s}^{-1}$ after the "Rammasun" landing in Fangchenggang City in Guangxi province, with the level clearly visible, weakening small.

Figures 5(d)-(f) are the vertical profiles of divergence corresponding to the time and location, and the strong convergence mainly concentrated in the 800 $\mathrm{hPa}$ below. Among them, at 14:00 on July 18, the center divergence was $-25 \times$ $10^{-6} \mathrm{~s}^{-1}$ before the arrival of the "Rammasun". At 8:00 on July 19, after landing in Fangchenggang City of Guangxi, the divergence of the center was $20 \times 10^{-6} \mathrm{~s}^{-1}$, and the divergence value was slightly decreased in the two times. While the positive divergence value is about $10 \times 10^{-6} \mathrm{~s}^{-1}$, little change.

Figures $5(\mathrm{~g})-(\mathrm{i})$ are the vertical velocity profiles corresponding to the time and location, and the rising motion area is located in the center of the "Rammasun" and over the west. Figure 5(i) shows that at 8:00 on July 18, the upward movement of the "Rammasun" extended, blocked in the $500 \mathrm{hPa}$ layer, and westward. At 14:00 on July 18th, the ascending motion area was columnar and westward inclined, and it was up to $120 \mathrm{hPa}$. At 8:00 on July 19, landing in Fangchenggang City, Guangxi, the vertical speed increased significantly, with the 

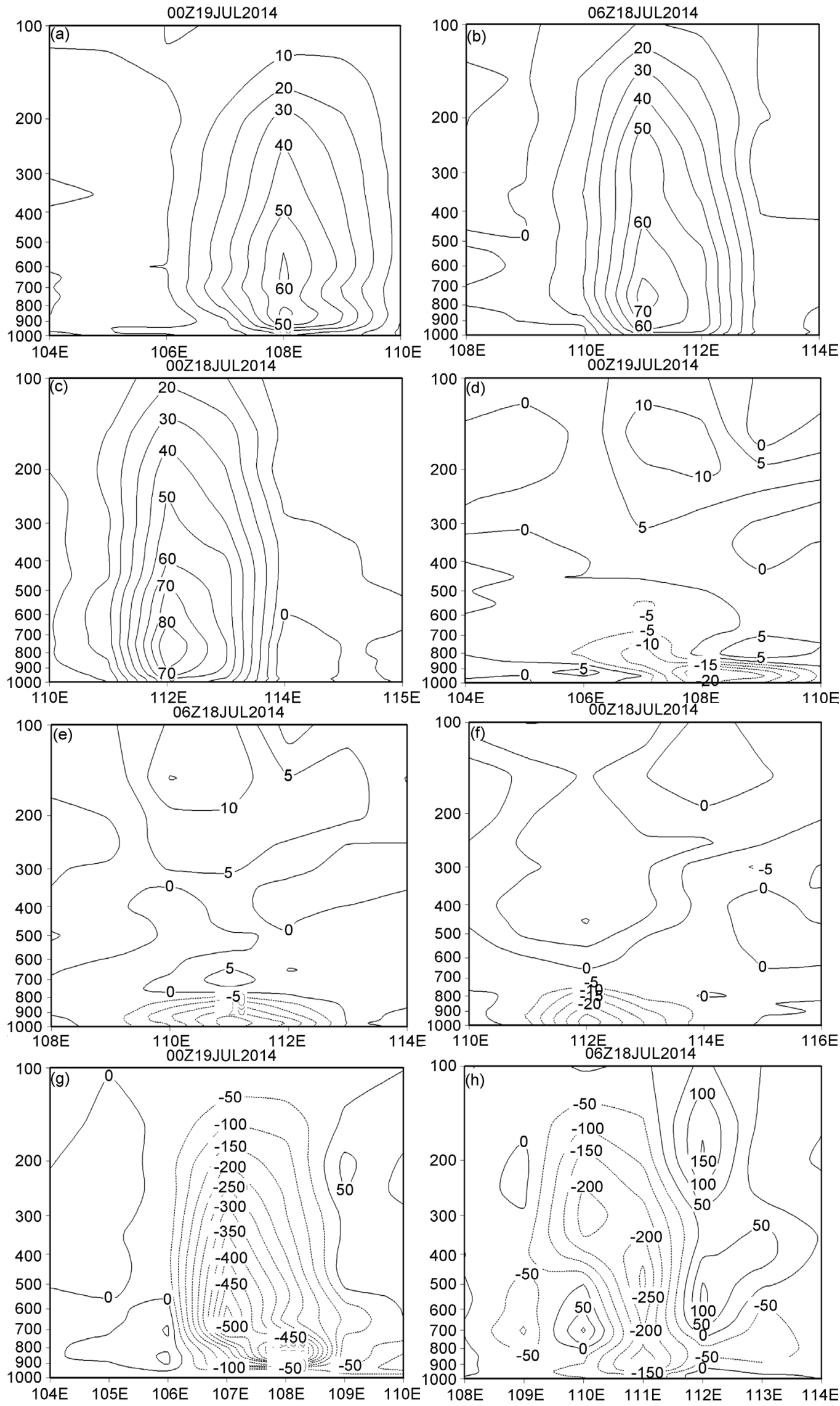


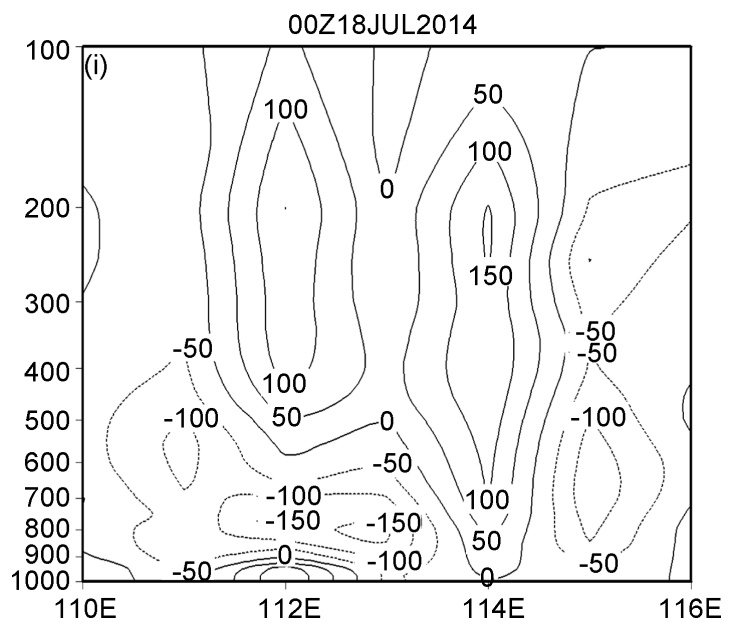

Figure 5. Vertical sections of vorticity, divergence and vertical speed in typhoon position (unit: vorticity $10^{-6} \mathrm{~s}^{-1}$, divergence $10^{-6} \mathrm{~s}^{-1}$, vertical speed $\left.\mathrm{hPa} \cdot \mathrm{s}^{-1}\right)((\mathrm{a}),(\mathrm{d}),(\mathrm{g}), 08: 00$ BT 19 July 2014; (b), (e), (h), 14:00 BT 18 July 2014; (c), (f), (i), 08:00 BT 18 July 2014).

rising movement of columnar upright and up to $100 \mathrm{hPa}$ height. The maximum values of the rising velocity at three times (Figures $5(\mathrm{~g})-(\mathrm{i})$ ) are around $850 \mathrm{hPa}$, $500 \mathrm{hPa}$ and $800 \mathrm{hPa}$, respectively. The maximum values are $1.5 \mathrm{hPa} \cdot \mathrm{s}^{-1}, 2.5$ $\mathrm{hPa} \cdot \mathrm{s}^{-1}, 5.5 \mathrm{hPa} \cdot \mathrm{s}^{-1}$, Showing an increasing trend.

The above analysis shows that after three landings, the "Rammasun" still maintain a high intensity, indicating that the subtropical high to strengthen the Southwest monsoon to carry water vapor and energy involved play an important role. In addition from the coastal to the landing of Fangchenggang City, Guangxi, vortex center only one, showing structure of the "Rammasun" is very complete dense and particularly intense. This phenomenon is also very rare in the process of typhoon. According to the vorticity equation (Li, et al., 2004) [6], this is the result of the coupling of the strong divergence column and the strong vorticity column. Under the background of favorable large-scale circulation, it is easy to form strong vertical uplift and more favorable for the occurrence and maintenance of heavy rain, which is an important dynamic mechanism for the occurrence and development of heavy rainfall. At the same time, the vertical rise of air column and vortex column coupling development, requires a strong convergence at low altitude. Low-level convergence will inevitably lead to strong positive vorticity generation, and then transported through the vertical movement to high altitude, so that the vortex column continues to strengthen. This is the force reason of the "Rammasun" in the northern Gulf region experienced three landing, and still causing Guangxi exceptionally strong winds and heavy rain.

\subsection{Water Vapor Condition Analysis}

The connection between water vapor transport channel and landfall typhoon is an important indicator of whether typhoon can sustain and cause heavy rain.

The horizontal distribution of water vapor flux divergence at $850 \mathrm{hPa}$ was 
analyzed from 20:00 on July 17, 14:00 on July 18 and 14:00 on July 19 at the location of the "Rammasun". See Figure 6. In the three time periods, the water vapor flux divergence was large in the low. The maximum values are all $14 \mathrm{~g} \cdot \mathrm{m} \cdot \mathrm{kg}^{-1} \cdot \mathrm{s}^{-1}$ at 20:00 on July $17,14: 00$ on July 18 and $14: 00$ on July 19 , showing that from the offshore to the landing Guangxi, the "Rammasun" Water vapor convergence has been very strong. The center of the water vapor flux in the vertical direction is near $850 \mathrm{hPa}$, and the center value is between $3.5-4.5 \mathrm{~g} / \mathrm{s}$, indicating that the water vapor carried by the "Rammasun" and the added water vapor are very sufficient, which is an important reason of leading to heavy rain along the coast of Guangxi.

\subsection{Latent Heat (Tq) Analysis}

Chen, et al. $(2001,2004)$ [7] [8] pointed out that latent heat release, transport and baroclinic potential energy release are the two main energy sources for the enhancement and maintenance of tropical cyclones offshore or landfall. The process of denaturation caused by the interaction of low-latitude systems is also beneficial to the strengthening and maintenance of storms. For the "Rammasun", the range of its activities is in the coastal waters of South China and not interacted with the middle latitude westerly. Therefore, it is the main energy source for the enhancement of the intensity of the "Rammasun" and the generation of the heavy rainstorm by the interaction of the latent heat with the monsoon

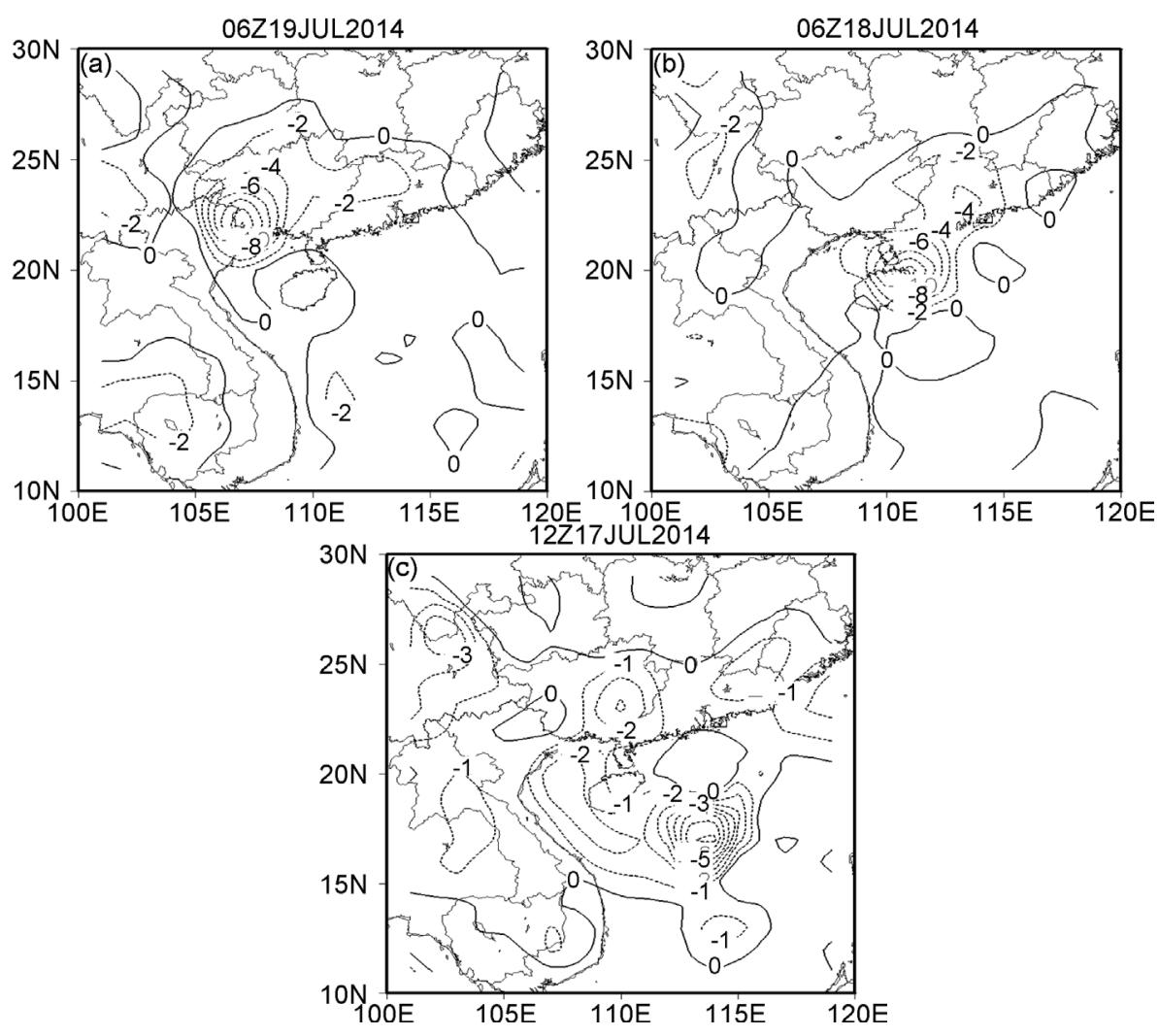

Figure 6. Rammasun water vapor flux divergence of 850 hPa ((a) 14:00 BT 19 July 2014; (b) 14:00 BT 18 July 2014; (c) 20:00 BT 17 July 2014). 
surge. The growth of latent heat is related to the transport of air around the jet stream, especially below $700 \mathrm{hPa}$ (Chao, 1998) [9].

In order to know more about the role of latent heat in the occurrence of strong wind and rain. Using latent heat energy formula (Tq) $\mathrm{Tq}=\mathrm{Lq} / \mathrm{Cp}$ ( $\mathrm{L}$ is the latent heat, $\mathrm{q}$ is the specific humidity, $\mathrm{Cp}$ is the specific heat of constant pressure) to calculate the latent heat change from $700 \mathrm{hPa}$ to $17 \mathrm{~h}$ on July 17 19. The results show that the period from 20:00 July 18 to 02:00 July 19 is the critical time for latent heat to be transported to the "Rammasun" circulation (Figure 7). In Figure 7(c) (at 14:00 on July 18), 25,000 j. $\mathrm{kg}^{-1}$ contours enclose the "Rammasun" and the left $25,000 \mathrm{j} \cdot \mathrm{kg}^{-1}$ contours are close together but not connected together. At 20:00 on July 18 (Figure 7 (b)), the $25,000 \mathrm{j} \cdot \mathrm{kg}^{-1}$ contour line surrounding the "Rammasun" has been connected to the $25,000 \mathrm{j} \cdot \mathrm{kg}^{-1}$ contour on the left to form a trough-like confluence Area, and monsoon energy transmission area connected into one. At 2:00 (July 7), the latent heat is transported to the west side of the Vermacon in the Beibu Gulf, and the latent heat is transported to the "Rammasun" circulation. Corresponding to the Guangxi heavy rain occurred.

Thus, the latent heat is particularly important reason that the "Rammasun" maintains greater strength, results in strong winds and heavy rain.

\subsection{Analysis of Meso-Scale Pressure Field}

The "Rammasun" in both sides of the Qiongzhou Strait has landed Hainan Wenchang and Guangdong Xuwen into the northern Gulf of the sea, with the friction loss in the process, so that the intensity weakened. In order to understand the

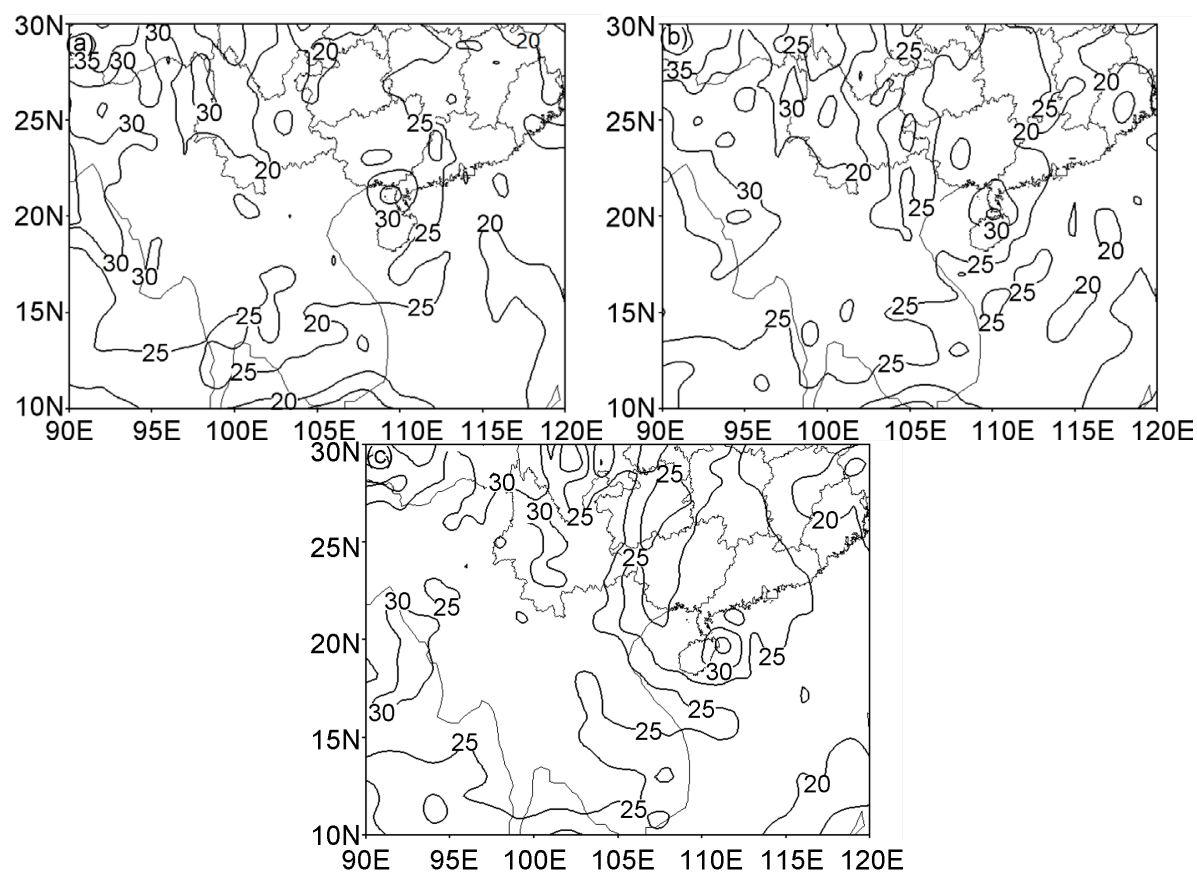

Figure 7. Rammasun latent heat energy of $700 \mathrm{hPa}$ (unit: $10^{3} \mathrm{j} \cdot \mathrm{kg}^{-1}$ ) ((a) 02:00 BT 19 July 2014; (b) 20:00 BT 18 July 2014; (c) 14:00 BT 18 July 2014). 
intensity change of the typhoon entering the Beibu Bay after Leizhou Peninsula to Hainan Island, and the intensity of 40 typhoons from 1970 to 2014 [10] [11] [12]. The results show that the central wind speed drops $7.75 \mathrm{~m} \cdot \mathrm{s}^{-1}$ and the central air pressure rises $12.4 \mathrm{hPa}$ after the typhoon enters Beibu Gulf.

Re-analysis from the Qiongzhou Strait (center through the Strait) into the northern Gulf of typhoon. A total of nine from 1970 to 2014 (Table 2). These typhoons from the Qiongzhou Strait into the North Bay, with the average wind speed down $2.9 \mathrm{~m} \cdot \mathrm{s}^{-1}$ and the central air pressure increased $8.8 \mathrm{hPa}$ on average. The results show that the intensity of the typhoon entering the Beibu Gulf from this channel is obviously weaker than the above average.

From the super typhoon case analysis, from 1970 to 2014, three super typhoons landed in Beibu Bay, namely 7314 (Maji), 0518 (Dawei), 1409 (The "Rammasun"). After the first two super typhoons entered Beibu Gulf, the central wind speed decreased by $25 \mathrm{~m} \cdot \mathrm{s}^{-1}, 22 \mathrm{~m} \cdot \mathrm{s}^{-1}$, and the central air pressure increased $60 \mathrm{hPa}$ and $40 \mathrm{hPa}$ respectively. The central wind pressure decreased by $8 \mathrm{~m} \cdot \mathrm{s}^{-1}$ and the central air pressure increased by $30 \mathrm{hPa}$, and the intensity weakened was also smaller than that in the first two cases. This fact also shows that the "Rammasun" went through low terrain of the Qiongzhou Strait, while other typhoons went through the mountain terrain. Qiongzhou Strait from east to west is about $80 \mathrm{~km}$, and the average width of north-south is $29.5 \mathrm{~km}$. On both sides of the Strait in addition to some high hills, the vast majority of 100 meters below sea level and the plains, and the average altitude of 50 meters. Low terrain and the channel channel is short, so that the "Rammasun" fast through, causing the friction loss is small, which is the important reasons that the "Rammasun" into the Gulf of Tonkin still maintain a large intensity.

\section{Conclusions}

The super typhoon the "Rammasun" of "1409" in 2014 is the strongest typhoon

Table 2. The typhoon intensity change from Qiongzhou strait into Beibu Gulf in 19702014.

\begin{tabular}{cccccc}
\hline Number & $\begin{array}{c}\text { Enter the } \\
\text { North Bay date }\end{array}$ & $\begin{array}{r}\text { Intensity before } \\
\text { entering }\end{array}$ & $\begin{array}{r}\text { Intensity after } \\
\text { entering }\end{array}$ & $\begin{array}{c}\text { wind speed variable } \\
\text { in center }\left(\mathrm{m} \cdot \mathrm{s}^{-1}\right)\end{array}$ & $\begin{array}{c}\text { air pressure variable } \\
\text { in center }(\mathrm{hPa})\end{array}$ \\
\hline 7109 & $6.27-28$ & 40,968 & 40,972 & 0 & +4 \\
8007 & $7.22-23$ & 40,965 & 30,975 & -10 & +10 \\
8217 & $9.14-15$ & 40,960 & 40,975 & 0 & +15 \\
8616 & $9.5^{08}-5^{20}$ & 40,960 & 40,970 & 0 & +10 \\
9111 & $8.16-17$ & 45,960 & 35,970 & -10 & +10 \\
9419 & $8.27-28$ & 30,980 & 35,975 & +5 & -5 \\
0312 & $8.25^{02}-25^{20}$ & 38,965 & 40,965 & +2 & 0 \\
1117 & $9.29^{14}-29^{02}$ & 40,965 & 35,970 & -5 & +5 \\
1409 & $7.18-19$ & 60,910 & 52,940 & -8 & +30 \\
Mean & & & & -2.9 & +8.8 \\
\hline
\end{tabular}


in South China since the "7314" super typhoon (Marchi) in 1973. During July 18 to 20 , it caused strong coastal areas of Guangxi strong winds and heavy rain, causing heavy casualties and property damage. The analysis indicates that the later subtropical high is rapidly strengthened, and the southwest monsoon and the cross-equatorial flow carrying water vapor and energy entrainment are the important reasons for the sudden strengthening of the "Rammasun" in the coastal waters. See Figure 8.

After entering the northern Gulf of Qiongzhou Strait, low friction consumption is an important reason that the "Rammasun" can still maintain the super typhoon intensity after into the North Bay.

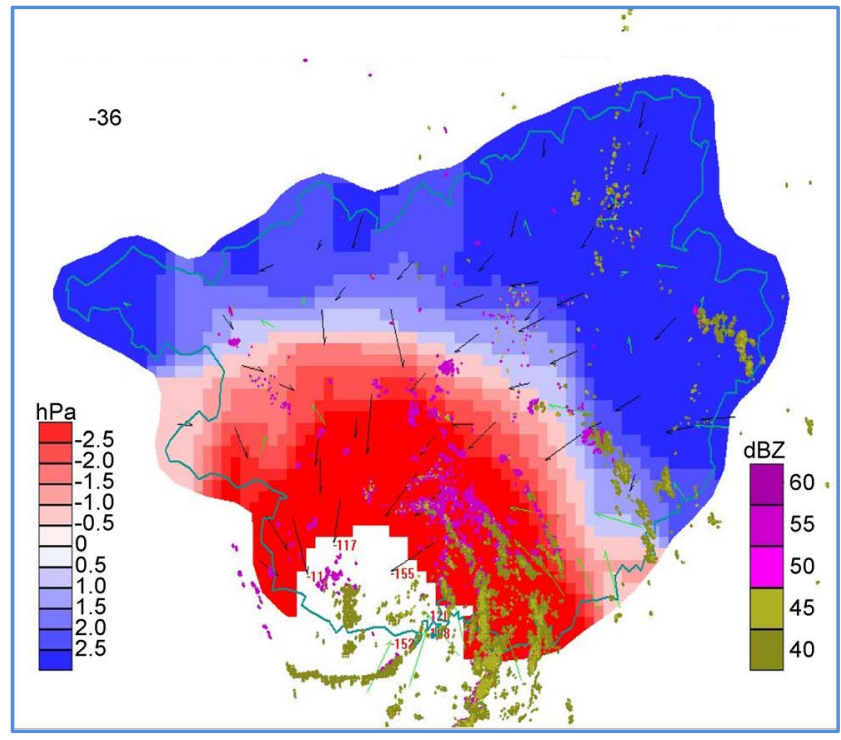

(a)

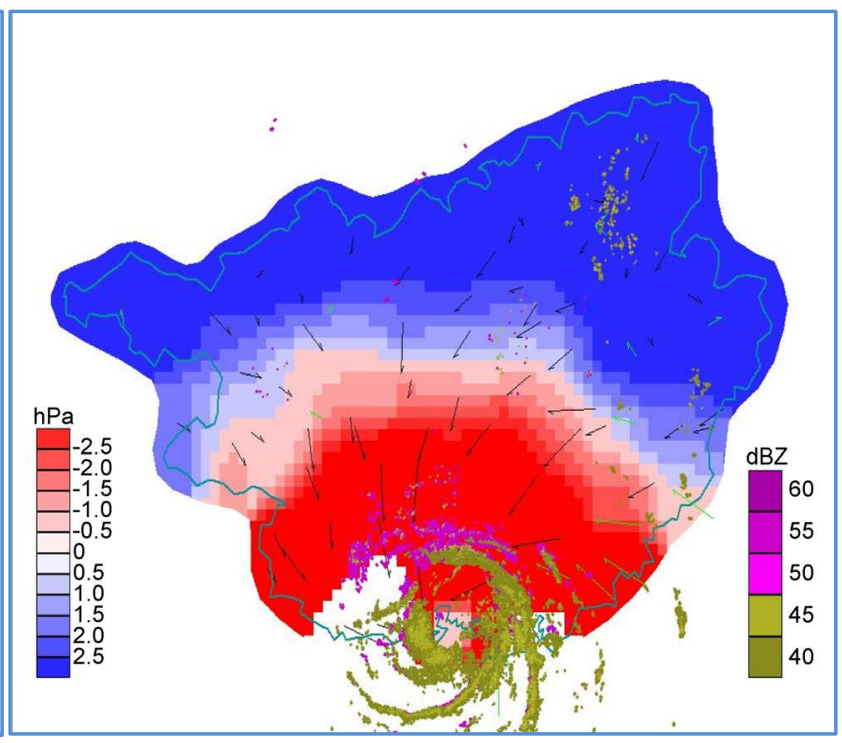

(b)

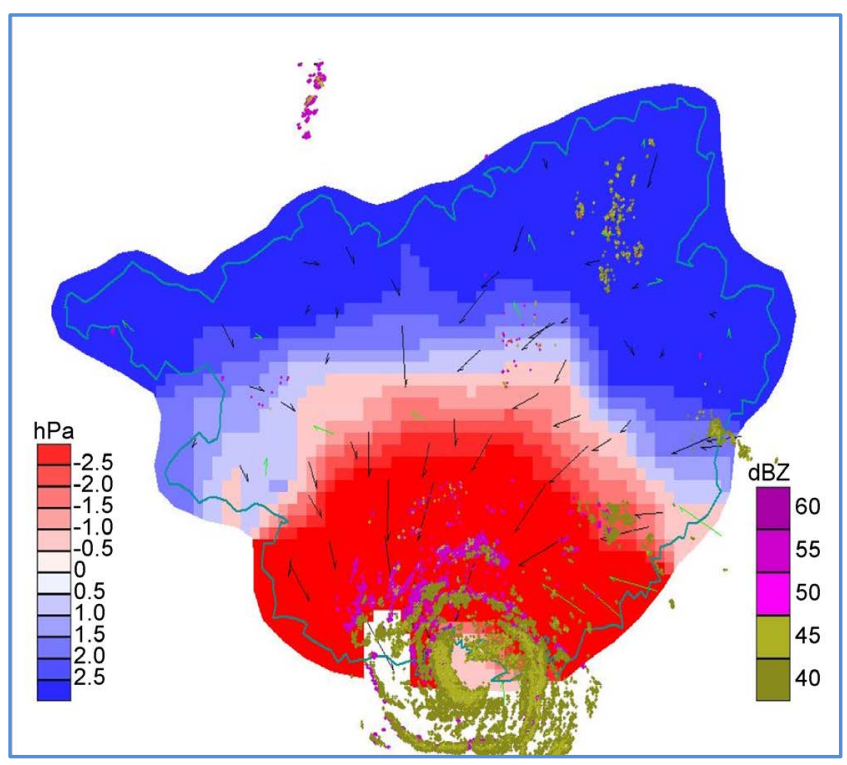

(c)

Figure 8. Mesoscale allobaric field and radar echo ((a) 11:00 BT 19 July 2014; (b) 07:00 BT 19 July 2014; (c) 06:00 BT 19 July 2014). 
The vorticity and divergence of the vorticity and divergence are weakened, and the vorticity column and the divergence column are clear, and the vertical ascending velocity is increased, and the water vapor flux divergence is large. The latent heat energy characteristic line is open to the west in the inverted trough, and merges with the latent heat of the monsoon jet transport, so that the vapor and energy of the "Rammasun" is the main reason causing the strong wind and the heavy rain.

After 3 times of landing, the "Rammasun" still maintains a great intensity, which is the result of the coupling of strong divergence column and strong vorticity column. Under the favorable large-scale circulation situation, the coupling development structure is easy to form strong vertical ascending motion, which is more favorable for the occurrence and maintenance of heavy rainstorm, which is an important dynamic mechanism for the occurrence and development of super-strong precipitation.

Although the typhoon can play a useful role in the elimination of drought, it is a very destructive weather system. In China's coastal areas, almost every year in both summer and autumn will be more or less affected by the typhoon invasion, so suffered the loss of life and property is also very serious. Strengthening typhoon monitoring and forecasting is an important measure to reduce typhoon disaster. Typhoon trail, intensity and landing forecast are the focus of typhoon forecast before typhoon landing. In the typhoon forecasting, the abrupt change of typhoon movement and velocity, the abrupt change of structure and intensity and the sudden increase of landing typhoon rain often bring great uncertainty to the anti-typhoon work. To this end, we must further strengthen the study of typhoon related scientific issues. Our researchers must constantly improve the typhoon path, strength, structural changes and heavy rainfall distribution and other related physical mechanisms of understanding, in-depth understanding of different scales and different latitudes of the interaction of the impact of typhoon; typhoon numerical model to enhance the typhoon collection or typhoon collection or Development and improvement of integrated forecasting system. Departments to further improve the typhoon and its disaster monitoring system construction, attention to a variety of unconventional detection techniques and means in the typhoon monitoring and forecasting applications in order to improve the landing typhoon monitoring and forecasting of the fine level of warning.

\section{Acknowledgements}

This study was funded by the Guangxi Natural Science Fund, China (Project Task No. 2015GXNSFAA139235).

\section{References}

[1] Duan, Y.H., Yu, H. and Wu, R.S. (2005) Review of the Research in the Intensity Change of Tropical Cyclone. ACTA Meteorologica Sinica, 5, 636-645.

[2] Kong, N.Q., Chen, R.M. and Cai, M. (2007) Analysis on Climatic Characteristics of 
Tropical Cyclone'S Intensity Catastrophe in Northen South China sea. Journal of Oceanography n Taiwan Strait, 2, 188-196.

[3] Hu, C.M., Duan, Y.H., Yu, H., et al. (2005) The Diagnostic Analysis of the Rapid Change in Tropical Cyclones Intensity before Landfall in South China. Journal of Tropical Meteorology, 4, 377-382.

[4] Tie, W.H., Jiang, M. and Shan, X.L. (2013) The Physical Decomposition Principles on Atmosphere Variables and Their Application in the Analysis of Regional Rainstorms. Meteorological Monthly, 5, 537-542.

[5] Qian, W.G., Jiang, M. and Shan, X.L. (2013) Physical Decomposition Principle of Atmospheric Variables and Its Application in Regional Rainstorm Analysis. Meteorology, 39, 537-542.

[6] Li, Y., Chen, L.S. and Wang, J.Z. (2004) The Diagnostic Analysis on the Characteristics of Large Scale Circulation Corresponding to the Sustaining and Decaying of Tropical Cyclone after It's Landfall. ACTA Meteorologica Sinica, 2, 169-179.

[7] Chen, L.S. (2004) Research Advances on Tropical Cyclone Landfall Process. ACTA Meteorologica Sinica, 5, 541-549.

[8] Chen, L.S. and Meng, Z.Y. (2001) An Overview on Tropical Cyclone Research Progress in China during the Past Ten Years. Chinese Journal of Atmospheric Science, 3, 420-432.

[9] Chao, S.Z. and Qiu, Y.Y. (1998) The Total Energy Variation during the Northward after Typhoon 9608 Landfall over China and the Maintenance of Bohai Japanese Sea High. ACTA Meteorologica Sinica, 6, 3-10.

[10] Lin, Z.G., Lin, K.P., Li, Y.X., et al. (2011) A Study of the Development Process of a Mesoscale Convective System ahead of a Upper Level Trough and Its Mechanism. ACTA Meteorologica Sinica, 5, 770-781.

[11] Lin, Z.G., Lin, M. and Lin, K.P. (2014) Principles and Applications of Monitoring and Early-Warning Products for Strong Rainfall. Journal of Meteorological Research and Application, 2, 23-26.

[12] Yan, J.Y., Zhang, X.Z., Chen, Q.J., et al. (1995) The Standard of Rapidly Intensified Tropical Cyclones. ACTA Meteorologica Sinica, 5, 9-13.

Submit or recommend next manuscript to SCIRP and we will provide best service for you:

Accepting pre-submission inquiries through Email, Facebook, LinkedIn, Twitter, etc. A wide selection of journals (inclusive of 9 subjects, more than 200 journals)

Providing 24-hour high-quality service

User-friendly online submission system

Fair and swift peer-review system

Efficient typesetting and proofreading procedure

Display of the result of downloads and visits, as well as the number of cited articles

Maximum dissemination of your research work

Submit your manuscript at: http://papersubmission.scirp.org/

Or contact gep@scirp.org 